\title{
İnovasyonun Yüksek Teknoloji Ürün İhracati Üzerindeki Etkisi: Yeni Endüstrileşen Ülkeler İçin Panel Veri Analizi
}

\section{The Effect Of Innovation On High Technology Product Export: Panel Data Analysis For New Industrial Countries}

\author{
Mehmet AKYOL, Gümüşhane Üniversitesi, Türkiye, mehmet_aykol81@ @hotmail.com \\ Orcid No: 0000-0002-1173-200X \\ Selim DEMEZ, Hakkari Üniversitesi, Türkiye, selimdemez@ windowslive.com \\ Orcid No: 0000-0001-6885-0499
}

\begin{abstract}
Öz: Yeni ürün ve üretim yöntemleri geliştirmek olarak tanımlanan inovasyon ile ülkeler yapısal değişim gerçekleştirmekte ve kalkınma hamlelerini hızlandırmaktadır. Inovatif faaliyetler sonucunda elde edilen yeni ürün ve üretim yöntemleri genellikle yüksek teknoloji barındırmaktadır. Yüksek teknoloji ürünler ise dış pazarlarda ülkelere rekabet gücü elde etme avantajı sağlamaktadır. Yüksek teknoloji ürün ihracatı yapan ülkeler ise döviz geliri sağlayarak ekonomik refah düzeylerini arttırmakta, neticede büyüme ve kalkınma hız kazanmaktadır. Bunun neticesinde inovasyon, özellikle ekonomik durgunluk ve daralma dönemlerinde iş dünyasına ve hükümetlere çıkış kapısı olma görevi üstlenmektedir. Bu çalışmada inovasyonun yüksek teknoloji ürün ihracatı üzerindeki etkisi yeni endüstrileşen ülkeler grubu özelinde analiz edilmiştir. 1996-2015 yılları arası dönemi kapsayan ve söz konusu gruba dahil 8 ülkeyi içine alan çalışma sonucunda inovasyon faaliyetlerinin yüksek teknoloji ürün ihracatı üzerinde olumlu bir etki oluşturduğu gözlemlenmişstir.
\end{abstract}

Anahtar Sözcükler: Yüksek Teknoloji Ürünü, İnovasyon, Dış Ticaret Panel Veri Analizi

JEL Siniflandirmasi: C01, C23, 032

\begin{abstract}
Through innovation, which is defined as developing new products and production methods, countries are making structural changes and accelerating development moves. As a result of innovative activities usually new product and production methods are being obtained and mentioned product and production methods generally contains high technology. High-tech products provide the advantage of competitiveness to countries in foreign markets. Countries that export high-tech products have increased their economic welfare by providing foreign exchange income, and consequently economic growth and development are gaining momentum. Innovation is the gateway to the business world and governments, especially during periods of economic recession and contraction. In this study, the effect of innovation on the export of high technology products has been analyzed in terms of the group of newly industrialized countries. Analyze covers the period between 1996-2015 and includes 8 countries. As a result of the study it was observed that innovation activities have a positive effect on high technology product exports
\end{abstract}

Keywords: High-tech products, Innovation, Panel Data Analysis, Foreign Trade

JEL Classification: C01, C23, 032

\section{Giriş}

Schumpeter, inovasyonu ekonomik kalkınmanın gereği olan yapısal değişime yol açan yenilik olarak tanımlamaktadır. $\mathrm{Bu}$ bağlamda yeni ürün ve üretim yöntemlerinin geliştirilmesi, yeni pazarların oluşturulması, yeni hammadde ve yarı mamul üretim sahalarının bulunması ve tekelci yapıya yol açan veya yapıyı yıkan yeni sanayi yapısının ortaya konması inovasyonun gerekleri olarak karşımıza çıkmaktadır (Sledzik, 2013: 90).

İnovasyon, iş dünyasının ekonomik durgunluk ve daralmalardan kurtulmasına imkan sağlayan bir anahtar görevi görmektedir. Küçük veya büyük ölçekli olmasına bakılmaksızın birçok yüksek teknoloji ürün üreticisi firma üretmiş oldukları ürünlerini geliştirmek ve bu ürünlere yeni pazarlarda yer açmak adına firsatları değerlendirmeye çalışmaktadırlar (Kim ve Huarng, 2011: 1147). İnovasyon ayrıca firmaların rekabetçi piyasada varlıklarını devam ettirmelerinde önemli rol oynamasının yanısıra aynı zamanda toplumsal ve sosyal anlamda dönüşüme de katkı sağlamaktadır (Sorensen ve Stuart, 2000:81).

İnovasyon ve yeni ürünler geliştirme çabalarının firmaların ticari başarılarının devamı açısından yaşamsal bir öneme sahip olduğu ileri sürülebilir. Yeni ürün geliştirme aşamasında sergilenen inovatif girişimler müşterilerin tercihlerinin ve ihtiyaçlarının giderilmesi anlamında firmaların performansını da olumlu şekilde etkilemektedir (Yalcinkaya vd., 2007: 66). İnovatif faaliyetlerin firmalara sağladığı bu gibi katkılar göz önüne alındığında son yıllarda inovasyon odaklı genç şirketlerin varlığı dikkat çekmektedir. Özellikle hızlı şekilde büyüyen ve yeni iş alanları oluşturan inovasyon odaklı ürün ve üretim yaklaşımı Schumpeteryan düşünce tarzı olan yapısal değişim ile yeniliğe ulaşma öğretisiyle son derece yakın benzerlik sergilemektedir (Coada vd., 2016: 387).

Yüksek teknoloji ürün üreten firmalar genellikle geliştirdikleri yeni ürün ve üretim yöntemlerini patentler ile koruma altına almaktadırlar. Patent uygulaması ile yenilikçi firmalar bir yandan yeni ürünlerini, rakipleri tarafindan piyasaya sürülecek olan sahtelerinden korurken diğer yandan da bu kısıtlama ile kendi üretim özgürlüklerini koruma duvarı ile 
çevrelemektedirler (Helmers ve Rogers, 2011: 1018). Bu açıdan patentler inovasyon sonucu elde edilen en önemli çıktı olarak da değerlendirilmektedir (Altuzarra, 2019: 180).

Coad ve Rao (2008) Ar-Ge harcamaları, makine, ekipman ve teknoloji satın alımları, endüstriyel tasarım ve teknoloji ile bağlantılı eğitim ve pazarlama faaliyetleri ile inovasyon çabalarının yakından ilişkili olduğunu ifade etmektedir. Söz konusu çabalar her ne kadar inovasyon ile yakından ilişkili olsa da inovasyonun somut etkisini görmek bazen uzun bir süreyi kapsamaktadır. Çoklukla inovasyon neticesinde elde edilen bilgi maliyet ve diğer zorluklardan dolayı hızlı şekilde üretim sürecine aktarılamamaktadır.

Yüksek teknoloji alanında elde edilen kazanımlar sektörün gelişimine katkı yapmakta ve bu bağlamda ekonomik refah seviyesinin arttırılmasına da imkan sağlamaktadır. Ekonomik refah seviyesinin yükselmesi ise doğrudan ekonomik büyüme üzerinde pozitif etki oluşturmaktadır. Bu açıdan, teknoloji geliştirme kapasitesinde meydana gelen artış ile ekonomik büyüme arasında doğru bir ilişki olduğu ileri sürülebilir (Harbi, vd., 2009: 465). Bununla birlikte teknoloji geliştirme çabası ve neticesinde elde edilen yüksek teknoloji üretkenliği ekonomik büyüme yanında kalkınma hamlelerinin ivme kazanması, ileri teknolojiyi yakalama ve ihracatın teşvik edilmesi gibi artı değerlerin hayata geçirilmesine öncülük etmektedir. (Baesu vd., 2015: 377)

Birçok ülke 2000'li yıllardan günümüze teknolojiye dayalı sanayi gelişimini sürdürmeye odaklanmıştır. Amerika Birleşik Devletleri'nde kurulu silikon vadisi yaklaşımı dünyanın farklı bölgelerinde mevcut örneğine uygun olacak şekilde oluşmaya başlamıştır. Yine yaklaşık yarım asırdır birçok Batı Avrupa ülkesi tarafından girişim sermayesi firmaları ve yeni açılan üniversiteler yolu ile müteşebbis merkezleri oluşturulmuştur. Japonya ülke genelinde araştırma şehirleri kurarken Çin teknoloji sahalarının gelişmesi adına teşvikler sunmaktadır. Singapur ise yüksek teknoloji fırsatlarını değerlendirmek adına deniz aşırı ülkelerde sıfır noktasından girişimciliğe adım atan şirketler aracılığı ile yatırımlarına yön vermektedir (Seyoum, 2004: 146).

Howells and Michie (1998), ticarileştirilmemiş inovasyon faaliyetlerinin sınırlı ölçüde değer oluşturacağını ileri sürmektedirler. Teknoloji açısından gelişmiş ülkeler elde ettikleri teknolojiyi çeşitli nedenlerle üretim sürecine dönüştürememektedirler. Üretim sürecine yansımayan teknolojik gelişme ise ticari alanda o ülkenin katma değer ve fayda sağlamasının önünde büyük bir engel oluşturmaktadır. Bu duruma örnek olarak Sigurdson ve Reddy (1995) tarafından yapılan çalışma gösterilebilir. Söz konusu çalışmada İsveç üniversitelerinde geliştirilen lazer yazıcı teknolojisi İsveç sanayisine entegre edilememiştir. Söz konusu entegrasyonun başarılı olmamasının geri planında ise geliştirilen teknolojinin absorbe edilmesi veya geliştirilen teknolojinin ticrileştirilmesi için gerekli olan kaynakların sağlanamaması gibi faktörler yatmaktadır.

\section{2. İhracatta Yüksek Teknolojinin Önemi}

Son yarım asırlık dönemde gayri safi milli hasılanın ve üretkenliğin arttırılmasında ihracat önemli bir yer tutmaktadır. Bu açıdan ihracatın daha fazla geliştirilmesinde ülke hükümetleri teşvik edici politikalar uygulamaktadırlar. Nitekim son y1llarda yüksek teknoloji alanında ortaya konan üretim ve ihracat süreçleri inovasyonun, teknoloji yoğun ürün ticaretinin ve bunların neticesinde elde edilen ekonomik performansın önemini gözler önüne sermiştir (Tebaldi, 2014: 343). İhraç ürünlerinde yüksek teknolojinin payının artması üretim çıktısında inovasyonun önemli bir ölçütüdür. Diğer yandan yine Ar-Ge yatırımları ve harcamaları da inovasyonun bir başka göstergesidir (Falk, 2007: 1).

Yüksek teknoloji yoğun ürün ihracatı uluslararası ticaretin en hızlı büyüyen sektörünü oluşturmaktadır. Bu açıdan gelişmekte olan ülkeler tarafından ihraç edilen ürünlerin önemli bir kısmı yüksek teknolojiye sahip ürünlerden oluşmaktadır (Srholec, 2007: 228). Baesu vd (2015) yüksek teknoloji ürün ihracatının önemini birkaç başlık altında sıralamaktadırlar. Bunlardan ilki, yüksek teknolojiye sahip ürünler uluslararası ticarette en fazla büyüme ivmesi yakalayan ürünler olarak ön plana çıkmaktadırlar.

Yüksek teknoloji ürün üretimi hızlı değişim gösteren ve gelişmiş teknolojiden oluştuğu ve yetenek yoğun üretim sürecinden geçtiği için giriş engellerinin yoğun olduğu bir sektör olma özelliği sergilemektedir (Zhang, 2007). Ayrıca gelişmekte olan ülkelerde yüksek teknoloji ürün üretiminin arttırılmasına yönelik uygulamalar söz konusu ülkelerin ekonomik büyüme çabalarına da pozitif katkılar sağlamaktadır. Diğer yandan yine yüksek teknoloji ürün üreten firmalar günümüzdeki mevcut son teknolojiyi yakından takip ettiklerinden ve üretimde bu teknolojiden yararlandıklarından ileriki dönemlere dair ekonomik büyüme beklentileri yüksek olmakta ve bu beklenti yüksek teknoloji alanına daha fazla yatırım yapılmasına zemin hazırlamaktadır.

Sun ve Wang (2005), ihracatta başarı düzeyinin arttırılması için temelde ülkelerin bir takım karşılaştırmalı üstünlüğe sahip olmaları gerektiğini ifade etmektedirler. Bu açıdan bir yandan ürün ve üretim yöntemleri geliştirme adına yapılan Ar-Ge çalışmaları diğer yandan söz konusu çalışmalara bağlı olarak gelişen inovasyon yaklaşımı ülkeleri ve firmaları uluslararası ticari arenada bir adım öne çıkarmakta ve yukarıda bahsi geçen karşılaştırmalı üstünlüğe de örnek oluşturmaktadır. Yüksek teknoloji ürün ihracatı ülkeler arası rekabet edebilme becerisinin geliştirilmesi konusunda bilgi sahibi olunmasına yardımcı olurken inovasyonun, karşılaştırmalı üstünlük elde edilmesinde ne gibi bir etkisinin olduğu konusunda da pozitif katkılar sağlamaktadır (Tebaldi, 2014: 344).

Yüksek teknoloji ürün ihracatı gerçekleştirmek isteyen ülkeler eğer söz konusu üretimi elde etmek adına yeterli teknolojik gelişmişliğe sahip değillerse bu açığı teknoloji yatırımları yaparak veya dışarıdan teknoloji ithal etme yolu ile sağlamaktadırlar. Nitekim teknoloji ithalatı sayesinde yüksek teknolojiye sahip ürün üretiminin ve ihracatının artması beraberinde yüksek karlılık getirmektedir (Spulber, 2007: 2). Sonuç olarak teknoloji yatırımlarını hayata geçirmek amacıyla dış ticaretin geliştirilmesi aynı zamanda yüksek teknoloji ürün üretimi ve ihracatının önünü açmaktadır. 
Ekonomik büyüme, istihdam ve refah üzerinde önemli bir yeri olan ihracat, rekabetin hız kazandığı son yıllarda ancak verimlilik artışı ile kendisine yüklenilen misyonu yerine getirmektedir. Söz konusu verimlilik artışı da ihraç ürünlerinde teknoloji yoğun üretim kapasitesinin geliştirilmesiyle mümkün olabilmektedir.

İnovasyon çalışmaları ihracatta yüksek teknolojinin payının arttırılmasına katkı sağlarken yüksek teknoloji ihracatı da inovasyonun geliştirilmesine ve bu alandaki çalışmaların hızlandırılmasına katkı sağlamaktadır. Bu açıdan inovasyon ve yüksek teknoloji arasında karşılıklı ve pozitif bir ilişkiden söz etmek mümkündür.

\section{Literatür Taraması}

İnovasyon ve yüksek teknoloji ürün üretimi (teknoloji yoğun ürün) üzerine iktisat literatüründe birçok makaleye rastlamak mümkündür. Bu çalışmalardan bir kısmı inovasyonun uluslararası ticaret ve ihracat üzerindeki etkisini incelemekte iken diğer bir kısmı ise yüksek teknoloji ürün ihracatının belirleyicileri üzerine yoğunlaşmaktadır. İnovasyon geliştirme çabalarının yüksek teknoloji ürün ihracatı üzerinde sergilemiş olduğu etkilere dair çalışmalar ise literatürde sınırlı kalmaktadir.

İnovasyonun uluslararası ticaret ve ihracat üzerindeki etkisini inceleyen çalışmalardan ilki Soete’e (1987) aittir. Çalışmada OECD ülkeleri grubunda teknoloji yoğun üretim yapan endüstrilerin teknolojik performansları ile ihracat performansları arasında yakın bir ilişki olduğu ifade edilmiştir. Özçelik ve Taymaz (2004) ürün ve üretim sürecinde sergilenen inovatif davranışların ve Ar-Ge harcamalarının diş ticarette Türk firmalarına rekabet üstünlüğü sağladığını ifade etmektedir. Diğer yandan Roper ve Love (2002) yeni ürünler üretmek adına ortaya konan inovasyon aktivitelerinin Almanya ve İngiltere'nin ihracatı üzerinde olumlu etkileri olduğu sonucuna ulaşmışlardır. Basile (2001), ise inovasyonun İtalya'daki ihracata dayalı firmaların uluslararası pazarda rekabet güçleri üzerinde önemli bir etki oluşturduğunu ileri sürmüştür.

Literatürde yüksek teknoloji ürün ihracatının belirleyicileri üzerine yapılan çalışmalar da yer almaktadır. Nitekim Zhang (2007) bir ekonominin endüstriyel teknoloji kapasitesinde meydana gelen gelişmelerin söz konusu ülkenin ihracatı üzerinde olumlu etkiler ortaya koyduğunu belirtmekte iken Spulber (2008) tekonloji yoğun ürün ihracatının yeni buluşların etkinliğini, ürün çeşitliliğini ve ticarete konu mal miktarını arttırdığını ileri sürmektedir. Diğer yandan yine teknoloji yoğun ürün ihracatı dış ticaret neticesinde elde edilen geliri arttırarak ( Çin, Güney Kore, Japonya, Batı Avrupa ülkeleri vb gibi) ulusal hasılaya pozitif katkı sağlamaktadır.

İnovasyonun yüksek teknoloji ürün ihracatı üzerindeki etkilerine dair çalışmalara örnek olarak Pereira vd.(2013) gösterilebilir. Söz konusu çalışmada teknolojide meydana gelen değişmelerle uluslararası ticaret arasındaki ilişki 4 Batı Avrupa ülkesi (Belçika, İtalya, Almanya ve Fransa) özelinde değerlendirilmiştir. Teknolojik inovasyonun ihracat üzerindeki etkisi ülke düzeylerinde farklı sonuçlar vermektedir. Bu bağlamda Yüksek teknoloji ürün endüstrilerinde Almanya ve Fransa için teknolojik inovasyon ihracat üzerinde pozitif etki oluşturmaktadır. Sandu ve Ciocanel (2014) Avrupa Birliği ülkelerinde inovasyona dayalı (burada Ar-Ge harcamaları inovasyon göstergesi olarak kabul edilmiştir) büyüme stratejileri geliştirilmesinin rekabet gücünü arttırıcı bir etken doğurduğu kanaatine varmıştır. Fu vd (2011) firma düzeyinde sergilenen inovasyon çabalarının Çin'de faaliyette bulunan yerel firmaların ihracatı üzerinde pozitif fakat küçük bir etki oluşturmaktadır. Diğer bir ifade ile Çin’in teknoloji yoğun ürün ihracatında göstermiş olduğu başarının arkasında inovasyon çabalarının yoğun şekilde etkisi yoktur.

Liu ve Lin (2005) ise inovasyon faaliyetlerinin bir göstergesi olma niteliği taşıyan patentlerin yüksek teknoloji ürün üretimi ve ihracatında önemli bir yer tuttuğunu ifade etmektedir. Jing (2010) çalışmasında Çin'in yüksek teknoloji ürün sınıfına giren elektronik, bilgisayar ve ilgili endüstrilerinde inovasyon faaliyetlerinin endüstrinin verimliliğini arttırdığını ifade etmektedir. Sara vd (2012) inovasyon faaliyetlerinin yüksek teknoloji ihracatı üzerindeki etkisini 120 ülke özelinde değerlendirmiş ve ülkelerin sahip olduğu inovatif kapasitenin arttırılması neticesinde yüksek teknoloji ürün ihracatının da artacağı sonucuna ulaşmışlardır.

Kabaklarlı vd. (2017) OECD üyesi ülkelerde yüksek teknoloji ürün ihracatının belirleyicilerini analiz ettikleri çalışmada ülkelerin Ar-Ge harcamalarına ağırlık vererek ve doğrudan yabancı yatırım çekme yoluyla inovatif faaliyetlere ağırlık yönelmelerinin önemli olduğunu dile getirmektedir. Ayrıca Panchenko ve Voychak (2016) gelişmiş ülkeler ve AB ülkelerinden hareketle Ukrayna ekonomisinin yüksek teknoloji ürün ihracatını değerlendirdiği çalışmada Ukrayna'nın gelişmiş ülkeler tarafından ortaya konan inovatif deneyimlerden yararlanması gerektiği ve ulusal inovasyon sisteminin geliştirilmesi için gerekli adımların atılması üzerinde durulmaktadır. Zhang vd. (2018) Çin’de yüksek teknoloji ürün üretimine başlayan yenilikçi firmaların üretim sürecini analiz ettikleri çalışmada büyük ölçeğe sahip eski firmaların düşük çıktı seviyesine sahip oldukları sonucuna ulaşmışlardır. Yine çalışma sonuçları patentler yoluyla elde edilen inovasyonun verimliliğinin ve şirketlerin sergilediği ithalat ve ihracat faaliyetlerinin Çin yüksek teknoloji ürün firmalarının rekabet etme eğilimlerini ve piyasada tutunma olasılıklarını arttırabileceği kanaatine varılmıştır. Son olarak Chen vd. (2017) teknolojik inovasyonun yüksek teknoloji endüstriler üzerindeki etkisini Çin özelinde değerlendirmişlerdir. Analiz sonucunda teknolojik inovasyonun yüksek teknoloji ürün endüstrileri üzerindeki etkinliğinin düşük olduğu kanısına varılmıştır. 


\section{Veriler ve Metodoloji}

\subsection{Veriler}

Çalışma, (NIC) grubuna dahil olan Türkiye, Çin, Malezya, Meksika, Filipinler, Güney Afrika, Tayland, Brezilya olmak üzere verisine ulaşılabilen sekiz ülkeyi kapsamaktadır. Bağımlı değişken yüksek teknoloji ihracatı (lnHTE) iken, kişi başı GSYH (lnGDP), yerleşik ve yerleşik olmayanların toplam patent başvuruları (lnPA), yerleşik ve yerleşik olmayanların toplam marka başvuruları (lnTMA), fikri mülkiyet haklarını ifade eden (lnPR) ve ticari özgürlüğ̈̈ gösteren (lnTRF) serileri bağımsız değişkenler olarak kullanılmıştır. Veriler 1996-2015 yılları arasındaki dönemi kapsamakta olup modelde kullanılan değişkenler farklı birimlerden oluştuğundan doğal logaritmaları alınmıştır. Tablo-1'de modelde kullanılan verilere ait tanımlayıcı istatistikler verilmiştir.

Tablo 1. Tanımlayıcı İstatistikler

\begin{tabular}{|l|l|c|r|r|c|}
\hline Değişkenler & \multicolumn{1}{l}{ Göz. Say. } & \multicolumn{1}{l}{ Ortalama } & \multicolumn{1}{l}{ Std. Sapma } & \multicolumn{1}{l|}{ Min. } & \multicolumn{1}{l|}{ Max. } \\
\hline $\operatorname{lnHTE}$ & 160 & 10.121700 & 0.743059 & 8.439510 & 11.74823 \\
\hline $\operatorname{lnGDP}$ & 160 & 3.627598 & 0.319523 & 2.850900 & 4.119502 \\
\hline $\ln \mathrm{PA}$ & 160 & 3.978352 & 0.601734 & 2.922725 & 6.042128 \\
\hline $\operatorname{lnTM}$ & 160 & 4.711434 & 0.496567 & 3.967688 & 6.323130 \\
\hline $\ln \mathrm{PR}$ & 160 & 1.660970 & 0.130266 & 1.301030 & 1.845098 \\
\hline $\operatorname{lnTRF}$ & 160 & 1.839947 & 0.085730 & 1.301030 & 1.938520 \\
\hline
\end{tabular}

\section{2.. Metodoloji}

Analiz, panel veri yöntemi kullanılarak yapılmıştır. Panel veri analizi ülkeler bölgeler firmalar vb. gibi kesit gözlemleri ile zaman serileri gözleminin birlikte analiz edilmesi yöntemidir. Panel veri analizinde ilk olarak klasik model, tesadüfi etkiler ve sabit etkiler modellerinden hangisinin seçileceğine karar verilmesi gerekmektedir. Birim etkinin olmadığını ifade eden sıfır hipotezine karşı F, LM ve LR testleri ile model sınanır. F testi panel veri modellerinde klasik modelin geçerli olup olmadığını, bir başka ifade ile birim veya zaman etkilerinin olup olmadığının sınandığı bir testtir. F testi ile verinin birimlere göre farklılık oluşturup oluşturmadığ 1 analiz edilmektedir. LR testi en çok olabilirlik testi olarak adlaındırılmakta ve klasik modelin tesadüfi etkiler modeline karşın test edilmesine imkan sağlamaktadır. LR testi tesadüfi etkiler ve klasik etkiler modellerini en çok olabilirlik yöntemi ile tahmin etmektedir. LM testi ise birim etkilerin varyanslarının sıfıra eşit olduğu durumu sınamaktadır (Tatoğlu,2012). Temel hipotezin reddedilmesi sonucunda sabit ve tesadüfi etkiler modelinden birinin geçerli olduğu anlaşılmaktadır. Sabit etkiler ile tesadüfi etkiler arasında seçim yapmak için Hausman testi kullanılmıştır (Baltagi, 2001:12). Bu aşamadan sonra otokorelasyon, değişen varyans ve birimlerarası korelasyon gibi temel varsayımlardan sapmaların olup olmadığının sınanması gerekmektedir. Tesadüfi etkiler modelinde otokorelasyonu test etmek için Durbin Watson ve Baltagi Wu testleri kullanılabilmektedir. Diğer yandan Levene, Brown ve Forysthe testi ile kurulan modelde değişen varyansın olup olmadığ 1 analiz edilebilmektedir. Tablo- 2 de df(7,152) (df serbestlik derecesini ifade etmektedir) serbestlik dereceli Snedecor F tablosu ile karşılaştırılarak birimlerin varyanslarının eşit olup olmadığı analiz edilmeye çalışılmıştır. Birimler arası korelasyon Pesaran testi ile araştırılmıştır. Bu durumda Baltagi ve Wu (1999) tarafindan önerilen ve tesadüfi etkiler GLS (genelleştirilmiş en küçük kareler) regresyonunda AR(1) (otoregresif süreci göstermekte ve birinci mertebeden otokorelayon) olduğu durumda kullanılan düzeltme modeli kullanılabilmektedir (Tatoğlu, 2012:221-230).

Kurulan model aşağıdaki şekildedir:

$\operatorname{lnHTE}_{\text {it }}=\alpha+\beta_{1} \operatorname{lnGDP}_{\mathrm{it}}+\beta_{2} \operatorname{lnPA}_{\mathrm{it}}+\beta_{3} \operatorname{lnTMA}_{\mathrm{it}}+\beta_{4} \operatorname{lnPR}_{\mathrm{it}}+\beta_{5} \operatorname{lnTRF}_{\mathrm{it}}+\varepsilon_{\mathrm{it}}$

Yukarıdaki denklemde t zamanı, i birimleri, $\alpha$ sabit terimi, $\beta$ eğim parametresini, $\varepsilon$ hata terimini ifade etmektedir.

Tablo 2. Regresyon Analiz Sonuçları

\begin{tabular}{|l|l|l|l|l|}
\hline InHTE (Bağımlı Değişken) & Katsayı & Std. Hata & $\mathbf{z}$ & $\mathbf{P}>\mathbf{P}|\mathbf{z}|$ \\
\hline Sabit Terim & $5,67^{*}$ & 0,66 & 8,63 & 0.000 \\
\hline $\operatorname{lnGDP}$ & $0,55^{*}$ & 0,1 & 5,43 & 0.000 \\
\hline $\operatorname{lnPA}$ & $0,21^{*}$ & 0,06 & 3,6 & 0.000 \\
\hline $\operatorname{lnTMA}$ & $0,08^{* * *}$ & 0,04 & 1,89 & 0.059 \\
\hline $\operatorname{lnPR}$ & 0,1 & 0,2 & 0,48 & 0.629 \\
\hline $\operatorname{lnTRF}$ & $0,58^{*}$ & 0,2 & 2,96 & 0.003 \\
\hline Resgresyon Denklemine İlișkin Diğer Testler & & & \\
\hline
\end{tabular}


Akyol, M., Demez, S. / Journal of Yasar University, 2020, 15/57, 56-62

\begin{tabular}{|l|l|l|l|l|}
\hline Gözlem Say1s1 & 160 & Baltagi Wu & 0,95 & \\
\hline Birim Say1s1 & 8 & & & \\
\hline \multirow{3}{*}{ Levene, Brown, Forysthe } & $\mathrm{W}_{0} \mathrm{df}(7,152)$ & $3,27^{*}$ & $\mathrm{P}>\mathrm{F}=0.003$ & \\
\cline { 2 - 5 } & $\mathrm{W}_{50} \mathrm{df}(7,152)$ & $2,75^{* *}$ & $\mathrm{P}>\mathrm{F}=0.010$ & \\
\hline & $\mathrm{W}_{10} \mathrm{df}(7,152)$ & $3,26^{*}$ & $\mathrm{P}>\mathrm{F}=0.003$ & \\
\hline Breuch ve Pagan LM testi & $983,56^{*}$ & & & \\
\hline Pesaran & $4,3^{*}$ & $\mathrm{P}=0.0000$ & & \\
\hline Wald testi chi2(6) & $111,79^{*}$ & & & \\
\hline \multicolumn{1}{|c|}{$\mathrm{R}^{2}$} & 0,78 & & & \\
\hline $\mathrm{F}(7,147)$ & $489,82^{*}$ & & & \\
\hline Hausman Pr>Chi2=0.2927 & 6,14 & & & \\
\hline DW (Durbin Watson ) & 0,75 & & & \\
\hline
\end{tabular}

Not: *,**,*** sırasıyla $\% 1, \% 5$ ve $\% 10$ düzeyinde anlamlılık seviyelerini göstermektedir.

Tablo 2'de HTE değişkeninin bağımlı değişken olduğu panel regresyon analiz sonuçları görülmektedir. F testi le modelde birim etkinin varlığına bakılmakta ilgili modelde birim etki varsa klasik modelin geçerli olmadığını ifade etmektedir. F testi sonuçları modelde birim etkinin olduğunu, diğer bir ifadeyle klasik modelin geçerli olmadığını göstermektedir. Hausman testi tesadüfi etkiler modeli ile sabit etkiler modeli arasında seçim yapmak için kullanılmaktadır. Sıfır hipotezi sabit etkiler modelinin geçerli olduğu ve kullanılması gerektiğini ifade ederken alternatif hipotez tesadüfi etkiler modelinin kullanılması gerektiğini ileri sürmektedir. Test sonuçları tesadüfi etkiler modelinin daha etkin ve tutarlı olduğunu göstermiştir. DW (Durbin-Watson)ve Baltagi-Wu test sonuçları 2'den küçük olduğu için modelde otokorelasyon problemi vardır. Ayrıca Levene, Brown, Forysth test istatistikleri modelde değişen varyansın olmadığını ortaya koymuştur. Ayrıca modelde birimler arası korelasyonun olduğu Pesaran testi ile anlaşılmaktadır. Diğer yandan chi2(6) serbestlik derecesinde wald testi modele dahil parametrelerin anlamlılı̆̆ını göstermektedir. chi2 ise gözlenen ve beklenen frekanslar arasındaki farkın istatistiki açıdan anlamlı olup olmadığını değerlendirmektedir. Hesaplanan test istatistiği parametre sayısına eşit (burada 6) serbestlik dereceli $\chi 2$ tablosu ile karşılaştırılarak test edilmektedir (Tatoğlu,2012:183).

Model sonuçları değerlendirildiğinde GDP'de ve TRF'de meydana gelen \%1'lik artışın HTE'yi \%0.6 oranında artırdığı görülmektedir. Ayrıca PA'da meydana gelen \%1 'lik artış HTE’yi \%0.21 oranında artırmakta, TMA'de meydana gelen \%1'lik bir artış ise HTE'yi \%0,08 oranında artırmaktadır. TRF'de meydana gelen \%1'lik bir değişim HTE'yi \%0,6 artırmakta iken son olarak PR değişkeni istatistiki olarak anlamlı değildir. Ayrıca modelde yer alan bağımsız değişkenler HTE'de meydana gelen değişimin \%78'ini açıklamaktadır.

\section{Sonuç}

Yüksek teknoloji, şirketlerin ve endüstrilerin tüm üretim sürecinde teknolojik altyapıdan ve yeniliklerden daha fazla yararlanmaları olarak ifade edilmektedir. Teknolojide ortaya çıkan ilerleme ülke ekonomilerini gelişme ve büyüme anlamında olumlu şekilde etkilemektedir. NIC üzerine yapılan ve yüksek teknoloji ihracatının bağımlı değişken olduğu çalışma sonuçları ticari özgürlüğün, Ar-Ge faaliyetlerini temsil eden toplam patent ve toplam marka başvurusunun kişi başı GSYH kadar önemli olduğunu ortaya koymuştur. Fikri mülkiyet hakları modelde anlamlı çıkmamıştır. Bunun nedeni henüz yeni endüstrileşen ülkelerde bu yapının gelişmiş ülkelerdeki kadar sağlam temeller üzerine inşa edilememesinden kaynaklanıyor olabilir. Çalışmadan elde edilen bulgular konu ile ilgili önceki çalışmaların sonuçlarını doğrular niteliktedir.

Küreselleşmenin hız kazanması, inovasyon faaliyetlerinin yaygınlaşması ve bunlara bağlı olarak bilgiye ulaşmanın kolaylaşması uluslararası piyasalarda rekabeti arttırıcı etki oluşturmaktadır. Gelişmiş ve gelişmekte olan ülkeler, bilgi ve teknolojik yeniliklere erişimin artması ile birlikte küresel piyasalardaki yüksek rekabet ortamında bir adım öne çıkabilmek için katma değeri yüksek ürün üretimi ve ihracatında birbirleri ile yarışmaktadırlar. Dünya ticaretinin daraldığı hatta sadece belli küresel güçlerin elinde olduğu yeni dünya düzeninde yeni ürün ya da yüksek teknoloji ürün üretimi sürdürülebilir büyümenin dinamiği niteliğindedir. Bu açıdan bakıldığında ülkeler yüksek teknoloji ürün üretimi ve ihracatının önündeki siyasal, politik ya da yapısal engelleri kaldırmanın yanı sıra Ar-Ge faaliyetlerine de büyük önem vermek durumundadirlar. 


\section{KAYNAKÇA}

Baesu Viorica, Albulescu Claudiu Tiberiu, Farkas Zoltan-Bela, Draghici Anca, 2015. "Determinants of the High-Tech Sector Innovation Performance in The European Union: A Review.” Procedia Technology 19:371-78

Baltagi, Badi H., Wu, Ping X., 1999. “Unequally Spaced Panel Data Regressions with AR (1) Disturbances.” Econometric Theory, 15 (6): 814-23.

Baltagi, Badi., H. 2001, Econometric Analysis of Panel Data, New York: Jhon Wiley

Basile Roberto 2001, "Export Behaviour of Italian Manufacturing Firms Over the Nineties: the Role of Innovation." Research Policy 30, (8): 1185-1201.

Chen Heng, He Ping, Chang-Xiao, Zhang, Liu Qiang. 2017, “Efficiency of Technological Innovation in China’s High Tech Industry Based on DEA Method.” Journal of Interdisciplinary Mathematics, 6 (7): 1493-96

Coada Alex, Segarrac Agustí, Teruel Mercedes. 2016. "Innovation and Firm Growth: Does Firm Age Play A Role?" Research Policy 45: 387-400.

Falk, Martin. 2007, "High-Tech Exports and Economicgrowth in Industrialized Countries.” Applied Economics Letters, 1-4.

Fu Dahai, Wu Yanrui, Tang Yihong. 2011. "Does Innovation Matter for Chinese High-Tech Exports? A Firm-Level Analysis." Economics Discussion, Working Papers 11-21.

Harbi Sana, Amamou Mariam, Anderson Alistair R. 2009. "Establishing High-tech Industry: The Tunisian ICT Experience" Technovation 29: 465-480

Helmers, Christian., Rogers Mark. 2011. “Does Patenting Help High-Tech Start-Ups?” Research Policy 40: $1016-27$.

Howells Jeremy, Michie Jonathan. 1998. "Technological Competitiveness in An International Arena." International Journal of the Economics of Business 5, (3): 279-93.

Jing, Han. 2010, "An Empirical Analysis On China's High-Technology Industry Innovation Efficiency Based On SFA", Studies in Science of Science (çevrimiçi) erişim: 24.03.2019 http://en.cnki.com.cn/Article_en/CJFDTOTALKXYJ201003021.htm.

Kabaklarlı E., Duran M.S., Üçler Y.T., 2017. “The Determinants of High-Technology Exports: A Panel Data Approach For Selected OECD Countries" Dubrovnik International Economic Meeting, 3(1): 888-900

Kim, Sang-Hoon., Huarng, Kun-Huang. 2011. "Winning Strategies For Innovation and High-Technology Products Management." Journal of Business Research 64: 1147-50.

Liu Wen Hsien, Lin Ya-Chi 2005. "Foreign Patent Rights and High-Tech Exports: Evidence from Taiwan." Applied Economics, 37, 1543-1555.

Özçelik, Emre, Taymaz Erol 2004. "Does İnnovativeness Matter For International Competitiveness in Developing Countries?" The case of Turkish manufacturing industries 33:409-425.

Panchenko Yevgen, Voychak Mychola (2016). "State Support of the High-Tech Exports: Comparative Analysis and Lessons for Ukraine”. International Economic Policy. 2 (25):98-123

Pereira T. Elisabeth, Paulo Joao, Bento Cerdeira ve Priede Janis. 2013. "The Contribution of Technological Change on EU Exports.” Procedia - Social and Behavioral Sciences 99: 658 - 64.

Roper, Stephen ve James H. Love. 2002. Innovation and Export Performance: Evidence From The UK and German Manufacturing Plants." Research Policy, 31, 1087-102

Sara, S.T., Jackson, F.H., Upchurch, L. T. 2012. "Role of Innovation in Hi-Tech-Exports of a Nation", International Journal of Business and Management 7 (7): 85-93

Sandu, S., Ciocanel, B. 2014. "Impact of R\&D And Innovation on High - Tech Export." Procedia Economics and Finance, 15, $80-90$

Seyoum, Belay. 2004. "The Role of Factor Conditions in High-Technology Exports: An Empirical Examination." The journal of high technology management research 15.(1): 145-62.

Sigurdson, J. Reddy, P. 1995. "National Appropriation of University Innovations: The Failure of Ink Jet Technologies in Sweden” Technology Analysis \& Strategic Management, 7. 41-62

Sledzik, Karol. 2013. "Schumpeter's View on Innovation And Entrepreneurship.” SSRN Electronic Journal,

Soete, Luc. 1987. "The Impact Of Technological Innovation on International Trade Patterns: The Evidence Reconsidered." Research Policy 16,(2-4): 101-30.

Sorensen B. Jesper, Stuart E. Toby. 2000. “Aging, Obsolescence, and Organizational Innovation.” Administrative Science Quarterly 45 (1): 81-12.

Spulber, F. Daniel. 2008. "Innovation and International Trade in Technology." Journal of Economic Theory, 138:1-20.

Srholec, Martin. 2007. "High-Tech Exports from Developing Countries: A Symptom of Technology Spurts or Statistical Illusion?" Review of World Economics 143: 227-55.

Sun, Yifei., Wang, Hongyang. 2005. "Does Innovation Matter For Export In China's Rural Enterprises?:Empirical Evidences From Jiangsu." Asian Geographer, 24 (1-2): 1-15.

Tatoğlu Yerdelen, Ferda. 2012. Panel Veri Ekonometrisi, İstanbul: Beta Yayıncılık.

Tebaldi, Edinaldo, 2011. "The Determinants of High-Technology Exports: A Panel Data Analysis," Atlantic Economic Journal, 39 (4):343-53.

WIPO, World Intellectual Property Organisations, What is Intellectual Property, Publication no: 450(E) 
Akyol, M., Demez, S. / Journal of Yasar University, 2020, 15/57, 56-62

Zhang, Kevin Honglin. 2007. "Determinants of Complex Exports: Evidence From Cross-Country Data For 1985-1998." International Economics 60 (1): 111-22.

Zhang, Dongyang, Zheng, Dongyang, Ning Lutao 2018. Does Innovation Facilitatefirm Survival? Evidence from Chinese High-Tech Firms", Economic Modelling, 75, 458-468 